\title{
Análises dos distratores das questões de Física em Exames de Larga Escala $^{+*}$
}

Guilherme Stecca Marcom ${ }^{1}$

E. E. Prof. Antonio Alves Aranha

Doutorando do Programa Multiunidades em Ensino de Ciências e Matemática

UNICAMP

Valinhos - SP

Maurício Urban Kleinke ${ }^{2}$

Instituto de Física Gleb Wataghin - UNICAMP

Campinas - SP

\section{Resumo}

Geralmente os exames de larga escala são depreciados pela comunidade escolar, por serem provas consideradas somativas, onde os resultados observados na prova não retornam aos candidatos, não existe uma realimentação. Nesse trabalho nós buscamos apresentar análises, utilizados os resultados das pesquisas sobre as estratégias de solução de problemas, para compreender quais são as maiores dificuldades presentes entre os estudantes no que se refere aos conhecimentos de Física aferidos pelos exames de larga escala, utilizando como exemplo o Enem. Para tanto, serão analisadas as questões de Física classificados no objeto de conhecimento "o movimento, o equilíbrio e a descoberta das leis da física", para os anos de 2009 a 2012. Será analisado, também, os distratores mais assinalados pelos candidatos declarados concluintes do Ensino Médio da rede pública de ensino. Nossos resultados apontam a que alguns estudantes utilizam concepções não científicas na resolução das questões, apresentam dificuldades na transposição do problema para outro contexto, utilizam raciocínios intuitivos e formas simbólicas em questões que neces-

\footnotetext{
${ }^{+}$Analysis of issues of Physics distractors in large-scale tests

* Recebido: outubro de 2015. Aceito: fevereiro de 2016.

1 E-mail: gui.marcom@gmail.com

2 E-mail: kleinke@ifi.unicamp.br
} 
sitam de uma abordagem matemática para a resolução. Ao apresentar essas discussões esperamos fornecer uma análise das questões apresentando indicadores qualitativos e quantitativos das maiores dificuldades apresentadas pelos alunos na resolução de questões como as do Enem.

Palavras-chave: Avaliação; Distratores; Exames de Larga Escala e Ensino de Física.

\begin{abstract}
Generally, the school community depreciates large-scale tests because these are considered summative, in which the results observed do not return to the candidates, there is no feedback. In this work, we will show some analysis on the results of problem-solving strategies researches. In order to understand the greatest difficulties among students concerning the knowledge of Physics that are measured by large-scale tests, we used as an example the Enem (Exame Nacional do Ensino Médio). In this regard, we analyzed the questions of Physics classified in the object of knowledge "movement, balance and discovery of the laws of physics" for the years 2009-2012. Our results show that some students use nonscientific concepts to solve the questions, have difficulties in transposing the problem to another context, use intuitive reasoning and symbolic forms for questions that require a mathematical approach to be solved. In presenting these discussions, we aim to provide an analysis on the questions with qualitative and quantitative indicators of the main difficulties presented by the students in solving tests as Enem.
\end{abstract}

Keywords: Assessment; Distractors; Large Scale Exams and Teaching of Physics.

\title{
I. Introdução
}

A partir da promulgação da Lei de Diretrizes e Bases (LDB) de 1996 a educação escolar brasileira passou a atender um conjunto de quesitos legais que buscaram organizar e estruturar os currículos e os indicadores educacionais no Brasil. Essa lei definiu a necessidade de avaliação em todos os níveis educacionais, visando obter parâmetros e indicadores para as políticas públicas associadas à educação. Dentre as avaliações criadas a partir de 1996 temos como exemplos o Sistema de Avaliação da Educação Básica (SAEB) e o Exame Nacional do Ensino Médio (Enem). 
Tanto o SAEB quanto o Enem podem ser considerados exames de larga escala, os quais apresentam como características: uma matriz de referência que pressupõe um recorte curricular comum a todos os candidatos; questões de múltipla escolha (em geral); aplicação em condições as mais similares possíveis (BLACK, 2009; FERNANDES, 2009).

Atualmente, o Enem atinge milhões de candidatos que buscam acesso ao ensino superior, seja na esfera pública - participando do sistema unificado de vagas (Sisu), onde vagas de universidades públicas são disputadas a partir dos resultados do Enem - seja na esfera privada - disputando bolsas do PróUni ou financiamento estudantil pelo Fundo de Financiamento Estudantil (FIES).

Em sua criação o Enem buscava avaliar a formação geral ao término educação básica, a qual poderia ser compreendida como o domínio das competências básicas necessárias para o exercício da cidadania. Como consequência, a prova buscava estabelecer relações entre o conhecimento escolar e as necessidades práticas do cotidiano das pessoas (INEP, 2002).

A partir de 2009 esse exame foi modificado com o intuito de transformá-lo num exame de acesso ao sistema federal de ensino superior, através do Sisu. Para que a o exame fosse aceito, principalmente pelas universidades federais, foram realizadas uma série de modificações em sua estrutura, passando a apresentar dois dias de prova, com 180 questões de múltipla escolha e uma redação dissertativa. A partir desse ponto, o Enem torna-se uma prova com algumas características similares aos (antigos e atuais) vestibulares.

Ao se transformar em uma prova de acesso ao ensino superior, o Enem passou a ser alvo de maior atenção por parte de professores, alunos e pesquisadores. Essa maior atenção por parte dos pesquisadores conduziu a um maior número de pesquisas buscando analisar as questões da prova. No caso das questões de Física, a literatura apresenta algumas críticas contundentes (SILVEIRA; BARBOSA; SILVA, 2015; SILVEIRA; STILCK; BARBOSA, 2014; BASSALO, 2011). Essas críticas se focam na existência de possíveis erros de fundamentos de Física, tanto nas questões como também nas alternativas; constituindo-se assim em importantes ferramentas para refletir sobre a elaboração de questões contextualizadas.

Por outro lado, a defesa feita ao Enem se baseia principalmente: a) nas características avaliativas da prova, a qual busca um aluno capaz de utilizar de um conjunto de informações para solucionar um problema; b) no fato de ser uma avaliação presente no cotidiano da maioria das escolas; c) em possibilitar as mais diferentes análises sobre a educação nacional e d) ser uma prova com maior dedicação à sua solução por parte dos alunos (ANDRÍOLA, 2011; GONSALVES JR.; BARROSO, 2014; MARCOM, 2015; GOMES, 2010; GOMES; BORGES, 2009; TRAVITZKI, 2013). Assim sendo, não podemos desconsiderar que - apesar dos problemas relatados - o Enem está posto e influencia a nossa sociedade. Para além do processo seletivo, o exame traz consigo um conjunto amplo de informações sobre o desempenho e o status socioeconômico dos alunos que cursam ou já cursaram a educação básica.

É com base nos microdados do Enem e no conjunto de informações disponíveis que propomos um estudo sobre as principais dificuldades dos alunos em resolver questões de Física, 
a partir da análise das alternativas erradas indicadas pelos alunos. Esperamos ampliar as informações disponíveis sobre o desempenho em questões de exames de larga escala, tornando esses exames mais úteis para o processo de ensino-aprendizagem na educação básica. Olhar para os erros que os candidatos cometem significa revelar problemas mais profundos da aprendizagem e incitar soluções mais efetivas para a melhoria da qualidade do ensino (AUTOR 1, 2015). Dessa forma, a análise sobre os erros cometidos e seu retorno à escola aproximaria as avaliações como o Enem, classificadas como avaliações somativas, de uma avaliação com características formativas.

\section{Referencial teórico}

As pesquisas sobre as estratégias de solução de problemas preveem um conjunto de dificuldades associadas à resolução das questões de Física. Um primeiro enfoque nesse problema discute as estratégias utilizadas por novatos e especialistas (CHI et al., 1981; CHI et al., 1982; LARKIN et al., 1980; MALONEY, 2011; SABELLA; REDISH, 2007). Os novatos são mais suscetíveis a cometerem erros, principalmente na modelagem matemática (LARKIN, 1980; LOZADA et al., 2006; SHERIN, 2001). O modelamento matemática necessita equações, as quais causam maior dificuldade aos novatos que aos especialistas. Uma das interpretações possíveis para essa dificuldade é o conceito de forma simbólica (SHERIN, 2001), o qual está relacionado ao modelo mental que os alunos retêm das diferentes equações que tomam contato na educação básica. Sherin sugere possíveis problemas enfrentados pelos estudantes ao "montar" uma fórmula, mesmo conhecendo o conceito associado à mesma. Também as concepções não científicas impactam diretamente nas estratégias de solução de problemas (KOU et al., 2013; SABELLA; REDISH, 2007). Outras dificuldades que podem ser destacadas relacionamse com interpretar e analisar gráficos ou imagens (BEICHENER, 1994; HALE, 2000; KOHL; FINKELSTEIN, 2006). Como visto nesse parágrafo, conhecer as dificuldades apresentadas pelos novatos em suas estratégias de solução de um problema pode sugerir caminhos para compreender quais são os motivos e raciocínios que conduzem os candidatos a assinalarem uma alternativa errada.

De acordo com o INEP as questões do Enem devem promover um trabalho investigativo, reflexivo e de tomada de decisão sobre as situações-problemas propostas (INEP, 2010). Quando o candidato se defronta com uma situação problema, ele pode utilizar distintas estratégias de resolução. Contudo, em um exame como o Enem algumas estratégias implicam em escolha das alternativas incorretas, também conhecidas como distratores.

Em cada questão, as alternativas incorretas podem apresentar uma maior ou menor atração para os candidatos. Na elaboração das questões se espera que as alternativas incorretas representem possíveis raciocínios errôneos dos candidatos (INEP, 2010). A partir dessa premissa é possível - em alguns casos - inferir a linha de raciocínio utilizada na solução da questão. Para isso, nos apropriamos das ferramentas descritas na literatura como estratégias de solução 
de problemas para a análise das alternativas das questões, buscando identificar as possíveis origens dos erros cometidos pelos candidatos.

Ao solucionar uma situação problema, o especialista tem menor dificuldade, pois já resolveu problemas similares, seja em exercícios de fixação; seja em problemas de caneta e papel. Essa experiência prévia do especialista faz com que ele apresente maior conhecimento tanto conceitual quanto relativa às habilidades e competências necessárias - do que os novatos (CHI et al., 1981; CHI et al., 1982; LARKIN et al., 1980; MALONEY, 2011). No caso do Enem, bem como dos demais processos seletivos, na elaboração dos distratores os especialistas buscam prever as possíveis dificuldades dos novatos.

Segundo Larkin (1980) os novatos buscam, em sua memória, fórmulas para resolver o problema a partir dos dados apresentados no enunciado. Isso pode significar que esses indivíduos farão pouca ou nenhuma reflexão conceitual sobre a fórmula a ser utilizada, a qual é a representação de um conceito físico.

Sherin (2001) propõe como hipótese que os alunos aprendem a associar significados conceituais a certas estruturas de equações, é possível supor - por parte do aluno - a construção de um significado físico a partir da "forma" de uma equação, ou vice-versa. A "forma" da equação está relacionada à sua aparência, se é constituída de uma fração, ou uma soma de termos, etc. A associação entre a forma da equação e o conceito físico é o que Sherin descreve como forma simbólica a qual "representa a associação entre um esquema conceitual simples, com um arranjo de símbolos em uma equação" (SHERIN, p. 482, 2001). Um exemplo de forma simbólica pode ser visto na figura abaixo:

$$
\begin{gathered}
v=v_{0}+a \cdot t \\
v=\square+\square . \square
\end{gathered}
$$

Fig. 1 - Representação da fórmula simbólica da função do movimento uniformemente variado.

Caso as equações propostas pelos alunos contenham erros em sua estrutura simbólica (p. e., a falta de um expoente em uma variável) esse erro iria comprometer a solução, tornandose esse resultado errôneo um importante indicador das relações que os indivíduos fazem entre o conhecimento conceitual e as representações matemáticas desses conceitos.

Outra dificuldade apresentada pelos novatos são as análises e interpretações de gráficos e imagens (BEICHENER, 1994; HALE, 2000; KOHL; FINKELSTEIN, 2006). Sua pouca familiaridade com essas representações semióticas, os conduzem a buscar distintas formas de análise, tanto para gráficos como para imagens.

Quando um novato busca escolher a fórmula necessária para a resolução da situação problema, essa escolha também é influenciada pelas concepções não científicas existentes na matriz de conhecimentos ("framework") dos alunos (SHERIN, 2001). Para Clement (1994) os novatos se utilizam das concepções não científicas para resolver um problema de forma intuitiva, fugindo assim das resoluções matemáticas. As concepções não científicas atuam como estruturas de controle epistemológico, fazendo com que os novatos a utilizem na construção de 
suas representações físicas do problema (KOU et al., 2013; SADAGHIANI; AGUILERA, 2013; SABELLA; REDISH, 2007). Desta forma, as concepções não científicas são um dos grandes problemas para o Ensino de Física, pois essas substituem as concepções científicas, afetando assim o aprendizado dos novatos ou seu desempenho em uma avaliação, como é o caso do Enem.

Um exame como o Enem é classificado como uma avaliação somativa, a qual se caracteriza como uma prova cujo objetivo é gerar uma medida do conhecimento do aluno (BLACK, 2009). Os resultados desses testes não apresentam realimentação nem discussão individual com os participantes e muitas vezes são utilizados como instrumentos para a criação de níveis de excelência, bem como para a indicação do sucesso ou fracasso escolar (PERRENOUD, 1999).

Ao analisar as diferenças entre uma avaliação formativa (que prevê relações de ensinoaprendizagem para além do desempenho) e uma avaliação somativa, Taras (2010) propôs que a diferença fundamental entre os dois formatos de prova fosse a capacidade da prova fornecer uma realimentação ("feedback") para a comunidade escolar e/ou para os participantes.

No caso de uma prova de larga escala associada ao ambiente escolar Taras propõe que, caso seja possível fornecer algum feedback aos professores e/ou aos alunos - que realizaram essa prova - essa prova apresentaria características de uma prova formativa. Segundo Taras

A diferença entre a avaliação somativa e a avaliação formativa reside no fato de que a última é usada pelo aprendiz para atualizar e aperfeiçoar o trabalho (ou, no mínimo, para entender o que precisaria ser feito e como). A avaliação somativa, por sua vez, não exclui o feedback (ou “conhecimento dos resultados”), e até mesmo uma nota ou reação física é capaz de fornecer informações, ainda que mínimas (p. 128, 2010).

No caso da prova do Enem, esse feedback poderia ser construído a partir de uma avaliação das alternativas selecionadas, buscando compreender a escolha dos estudantes a partir de uma análise das possíveis estratégias de resolução e das frequências de resposta nas alternativas. Dessa maneira a avaliação somativa se aproximaria da avaliação formativa (TARAS, 2010), uma vez que os resultados das provas estariam sendo analisados e retornado a comunidade escolar, colaborando no processo de ensino-aprendizagem. Esse novo enfoque avaliativo para o Enem permite ressaltar suas características associadas a uma prova formativa.

Considerando que os distratores nas questões do Enem representam possíveis raciocínios errôneos em sua resolução; logo a escolha dessas alternativas erradas pelos alunos sugere que esses mesmos raciocínios errôneos também possam ser perceptíveis nas salas de aula do Ensino Médio.

A análise das questões nos permite obter informação sobre as dificuldades dos alunos, e mais do que isso, alguns indícios sobre a forma como os alunos aplicam seu ferramental de 
conhecimentos sobre Física nas questões do Enem. A partir da observação da alternativa escolhida, é possível inferir qual o tópico da formação do aluno que apresenta maior necessidade de maior atenção no ambiente escolar. Apesar desse retorno das informações obtidas no Enem não servir como devolutiva para os alunos que realizaram a prova, serve como devolutiva tanto para as escolas e professores quanto para os cursos de formação de professores. Desta forma, acreditamos que a prova do Enem, que é um exame somativo, também poderia vir a aproximar-se de um exame com características formativas.

\section{Metodologia}

Foram analisadas as provas de Ciências da Natureza dos anos de 2009 a 2012. Em cada prova foram classificadas - por dois especialistas - as questões associadas à área de conhecimento de Física. Essa técnica de categorização é conhecida como classificação por pares onde os autores categorizam de forma independente as questões e depois compararam os resultados (OLIVEIRA et al., 2013; GONSALVES JR.; BARROSO, 2014; MARCOM e KLEINKE, 2014; MARCOM e KLEINKE, 2015; MARCOM, 2015). As quatro provas apresentaram 63 questões associadas à Física, sendo que ocorreu discrepância na classificação em três questões, com uma confiabilidade próxima de $95 \%$.

A partir dos microdados disponibilizados pelo $\mathrm{INEP}^{3}$, os dados foram tratados no programa estatístico SAS 9.2 visando obter a frequência das alternativas assinaladas pelos candidatos em cada questão e em cada tipo de prova.

Optamos por selecionar apenas os candidatos concluintes do Ensino Médio em escolas públicas, uma vez que a maioria dos estudantes brasileiros estão nessa rede. Da mesma forma, que analisar esse grupo de candidatos possibilita fazer um acompanhamento do Ensino Médio público, avaliando se os alunos egressos das instituições públicas de ensino apresentam os conhecimentos esperado para esse faixa escolar.

Pode-se somar a esse motivo o fato do desempenho médio em Física dos candidatos oriundos das escolas públicas ser baixo, conforme evidenciam resultados de diversos estudos e provas, tais como o próprio Enem. A Tabela 1 abaixo apresenta o número de candidatos em cada ano analisado.

Tabela 1 - Número de candidatos selecionados em cada ano de aplicação do Enem.

\begin{tabular}{|c|c|c|c|c|c|}
\hline Ano & 2009 & 2010 & 2011 & 2012 & Total \\
\hline $\begin{array}{l}\text { Número de } \\
\text { Candidatos }\end{array}$ & 571.984 & 802.198 & 895.844 & 905.871 & 3.175 .897 \\
\hline
\end{tabular}

Como apresentar a discussão para as 63 questões não era possível, optamos em apresentar as questões pertencentes a um único Objeto do Conhecimento chamado "O Movimento,

\footnotetext{
${ }^{3}$ Disponível em: http://portal.inep.gov.br/basica-levantamentos-acessar
} 
o equilíbrio e a descoberta das leis da física". Para categorizar as questões nesse objeto do conhecimento também utilizamos a classificação por pares gerando um conjunto de 13 questões. A escolha dessa categoria se deve ao fato de que ela contém o maior número de conceitos físicos, segundo a Matriz de Referência do Enem (INEP, 2009).

\section{Resultados e análise dos dados}

$\mathrm{Na}$ apresentação dos resultados serão analisadas algumas questões, para as quais são apresentados: o enunciado; uma tabela onde consta o ano da aplicação e o número da questão na sequência apresentada pela prova de cor azul ${ }^{4}$; o número de alunos concluintes egressos da rede pública; e finalmente a frequência (expressa na forma de porcentagem) em cada alternativa. Alguns poucos candidatos não responderam à questão ou sua questão foi anulada, não sendo contabilizados na tabela. A coluna na tabela associada à alternativa correta está destacada por um fundo cinza e o percentual de frequência em negrito.

A primeira questão a ser analisada irá apresentar conceitos relativos à atuação da força centrípeta em um trem ao realizar uma curva.

\begin{tabular}{|c|c|c|c|c|c|c|}
\hline \multicolumn{4}{|c|}{$\begin{array}{l}\text { O Brasil pode se transformar no primeiro pais das } \\
\text { Américas a entrar no seleto grupo das nações que } \\
\text { dispõem de trens-bala. O Ministério dos Transportes prevê } \\
\text { o lançamento do edital de licitação internacional para a } \\
\text { construção da ferrovia de alta velocidade Rio-São Paulo. A } \\
\text { viagem ligará os } 403 \text { quilômetros entre a Central do Brasil, } \\
\text { no Rio, e a Estação da Luz, no centro da capital paulista, } \\
\text { em uma hora e } 25 \text { minutos. } \\
\text { Disponivel em: http:/loglobo.globo.com. } \\
\text { Acesso em: } 14 \text { jul. } 2009 \text {. }\end{array}$} & \multicolumn{3}{|c|}{$\begin{array}{l}\text { Devido à alta velocidade, um dos problemas a ser } \\
\text { enfrentado na escolha do trajeto que será percorrido pelo } \\
\text { trem é o dimensionamento das curvas. Considerando-se } \\
\text { que uma aceleração lateral confortável para os } \\
\text { passageiros e segura para o trem seja de } 0,1 \mathrm{~g} \text {, em que g } \\
\text { é a aceleração da gravidade (considerada igual a } 10 \mathrm{~m} / \mathrm{s}^{2} \text {, } \\
\text { e que a velocidade do trem se mantenha constante em } \\
\text { todo o percurso, seria correto prever que as curvas } \\
\text { existentes no trajeto deveriam ter raio de curvatura minimo } \\
\text { de, aproximadamente. }\end{array}$} \\
\hline Enem 2009 & $\mathbf{N}$ & A & B & $\mathrm{C}$ & D & $\mathbf{E}$ \\
\hline Questão 17 & 571.984 & $23,9 \%$ & $28,5 \%$ & $24,3 \%$ & $18,5 \%$ & $4,7 \%$ \\
\hline
\end{tabular}

Fig. 2 - Trem de alta velocidade Rio - São Paulo.

O objetivo da questão é que o aluno calcule o raio da curva do trajeto do trem, para que a aceleração lateral afete pouco os passageiros, tornado assim a viagem mais confortável. O raio de curvatura pode ser calculado a partir da fórmula da força centrípeta:

$$
\begin{gathered}
F_{c}=\frac{m v^{2}}{R}=m a \\
\frac{v^{2}}{R}=a
\end{gathered}
$$

\footnotetext{
${ }^{4}$ As provas são aplicadas utilizando quatro modelos (azul, amarelo, branco e cinza), onde a ordem das questões é variada. Os microdados foram descoloridos e transformados na sequência correspondente à prova de cor azul.
} 


$$
R=\frac{v^{2}}{a}=\frac{80^{2}}{0,1 g}=\frac{6400}{0,1 \times 10}=\frac{6400}{1}=6400 \mathrm{~m}
$$

A análise sobre os possíveis erros cometidos pelos alunos permite inferir que o distrator $(\mathrm{A}, 80 \mathrm{~m})$ indica apenas o cálculo da velocidade média do trem $(80 \mathrm{~km} / \mathrm{h})$ e utilizaram esse resultado numérico (80) como resposta, sem considerar a unidade associada à medida.

Já o valor observado na opção $(\mathrm{C}, 800 \mathrm{~m})$ é resultado de um duplo erro: um deles associado à representação da fórmula (utilizada como mv/R no lugar de mv2/R) e outro associado à leitura da aceleração (onde a indicação de $0,1 \mathrm{~g}$ foi indevidamente transformada em 0,1 $\mathrm{m} / \mathrm{s}^{2}$ em vez do valor correto de $1,0 \mathrm{~m} / \mathrm{s}^{2}$ ). Essas observações conduzem a um raio de curvatura igual a $800 \mathrm{~m}$. Provavelmente os candidatos nem perceberam que a aceleração lateral era fornecida em função da aceleração da gravidade, quase sugerindo um truque para forçar o erro dos alunos submetidos à prova, conhecido informalmente como "uma pegadinha".

Esses resultados sugerem que os alunos se utilizam de fórmulas com um parcial conhecimento sobre as mesmas, que pode ser traduzido pelo conceito de forma simbólica, o qual explicaria algumas das escolhas de alternativas incorretas por parte dos alunos (SHERIN, 2001). Existe uma grande probabilidade de que os alunos conheçam a forma simbólica da (fórmula da) força centrípeta

$$
\mathrm{F}_{c}=\frac{\square}{\square}
$$

Fig. 3 - Forma simbólica da força centrípeta.

Entretanto, eles têm dificuldades em identificar quais são as variáveis que compõem a fórmula, bem como se existe ou não uma variável com algum expoente. Isso explicaria o motivo pelo qual os alunos não utilizaram a velocidade do trem ao quadrado.

Para o distrator com a maior frequência de respostas (B, 430 m) não encontramos possíveis erros matemáticos ou de manipulação de fórmulas que levariam a esse resultado. Essa escolha, entretanto, nos sugere uma concepção cotidiana do que seja uma curva: os alunos sabem intuitivamente que uma curva, com um raio de $80 \mathrm{~m}$ seria muito abrupta para o trem; porém os valores maiores pareceriam excessivos para os alunos. Essa escolha indica uma possível busca por raciocínios intuitivos (CLEMENT, 1994) para a resolução do problema, evitando as soluções matemático-dedutivas.

Nossa próxima análise será sobre uma situação-problema de logística em uma empresa de transportes. 
Uma empresa de transportes precisa efetuar a entrega de uma encomenda o mais breve possível. Para tanto, a equipe de logística analisa o trajeto desde a empresa até o local da entrega. Ela verifica que o trajeto apresenta dois trechos de distâncias diferentes e velocidades máximas permitidas diferentes. No primeiro trecho, a velocidade máxima permitida é de $80 \mathrm{~km} / \mathrm{h}$ e a distância a ser percorrida é de $80 \mathrm{~km}$. No segundo trecho, cujo comprimento vale $60 \mathrm{~km}$, a velocidade máxima permitida é $120 \mathrm{~km} / \mathrm{h}$.
Supondo que as condições de trânsito sejam favoráveis para que o veículo da empresa ande continuamente na velocidade máxima permitida, qual será o tempo necessário, em horas, para a realização da entrega?

A 0,7

B 1,4

(C) 1,5

(D) 2,0

(E) 3,0

\begin{tabular}{|c|c|c|c|c|c|c|}
\hline Enem 2012 & N & A & B & C & D & E \\
\hline Questão 72 & 905.871 & 8,62 & 17,55 & $\mathbf{3 6 , 7 4}$ & 26,79 & 9,92 \\
\hline
\end{tabular}

Fig. 4 - Logística de uma transportadora.

Para responder de forma correta à situação-problema proposta os alunos necessitariam calcular o tempo de viagem em cada trecho (uma hora seguida de meia hora) e depois realizar uma simples soma de resultados. Analisando os distratores que mais atraíram os alunos buscamos inferir outras possíveis linhas de raciocínio para as respostas.

Os alunos que optaram pelo distrator $(\mathrm{D}, 2,0 \mathrm{~h})$ provavelmente solucionaram o problema utilizando algum raciocínio lógico ou ideia intuitiva (CLEMENT, 1994). Um possível raciocínio estaria associado à divisão de dois números presentes no enunciando $(60 \mathrm{~km}$ e 120 $\mathrm{km} / \mathrm{h}$ ), com um resultado igual a um número inteiro $(120 / 60=2)$, sem considerar as unidades. Alguns alunos utilizam essa estratégia de realizar operações matemáticas com os números do enunciado, buscando respostas com números inteiros, um pouco como resultado de uma aplicação errônea de exercícios de fixação.

Assinalar a alternativa (B, 1,4 h) sugere que a velocidade média do percurso seria expressa pela média entre as duas velocidades fornecidas $(80 \mathrm{Km} / \mathrm{h}$ e $120 \mathrm{Km} / \mathrm{h}$ ). Com uma velocidade de $100 \mathrm{Km} / \mathrm{h}$ e uma distância a ser percorrida de $140 \mathrm{~km}$, o tempo de viagem seria de $1,4 \mathrm{~h}$.

Nossa próxima análise será sobre uma questão relativa ao conceito e às formulações matemáticas sobre empuxo. 
Em um experimento realizado para determinar a densidade da água de um lago, foram utilizados alguns materiais conforme ilustrado: um dinamômetro $\mathrm{D}$ com graduação de $0 \mathrm{~N}$ a $50 \mathrm{~N}$ e um cubo maciço e homogêneo de $10 \mathrm{~cm}$ de aresta e $3 \mathrm{~kg}$ de massa. Inicialmente, foi conferida a calibração do dinamômetro, constatando-se a leitura de $30 \mathrm{~N}$ quando o cubo era preso ao dinamômetro e suspenso no ar. Ao mergulhar o cubo na água do lago, até que metade do seu volume ficasse submersa, foi registrada a leitura de $24 \mathrm{~N}$ no dinamômetro.

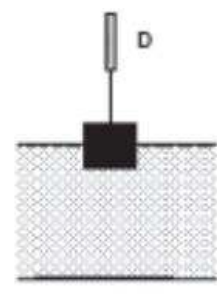

Considerando que a aceleração da gravidade local é de $10 \mathrm{~m} / \mathrm{s}^{2}$, a densidade da água do lago, em $\mathrm{g} / \mathrm{cm}^{3}$, é

A 0,6 .

(B) 1,2 .

C) 1,5 .

(D) 2,4 .

E 4,8 .

\begin{tabular}{|c|c|c|c|c|c|c|}
\hline Enem 2011 & N & A & B & C & D & E \\
\hline Questão 73 & 895.844 & $14 \%$ & $\mathbf{2 1 , 6 \%}$ & $23,1 \%$ & $30,7 \%$ & $10,1 \%$ \\
\hline
\end{tabular}

Fig. 5 - Densidade da água de um lago.

Uma resolução possível relaciona a força peso, a força resultante e a força de empuxo para determinar qual a densidade da água do lago. Para essa solução, uma primeira etapa consiste em encontrar o valor da força de empuxo (E) a partir dos valores da força peso (P) e força resultante $\left(\mathrm{F}_{\mathrm{r}}\right)$ :

$$
\begin{gathered}
P-E=F_{r} \\
E=P-F_{r} \\
6=30-24
\end{gathered}
$$

Em uma segunda etapa, é necessário calcular a densidade da água do lago a partir de valor encontrado para a força de empuxo $(6 \mathrm{~N})$. Existe a necessidade de trocar o sistema de unidades, pois a densidade é esperada $\mathrm{em} \mathrm{g} / \mathrm{cm}^{3}$.

$$
\begin{gathered}
E=6 N=6 \times 10^{5} d y n=\rho g V \\
\rho=\frac{6 \times 10^{5}}{10^{3} \times 10 \times 10 \times 5}=1,2 \frac{g}{\mathrm{~cm}^{3}}
\end{gathered}
$$

Um aluno com uma boa formação teria dificuldade em aceitar esse valor de densidade para a água, pois é muito elevado. Nota-se que o processo de resolução dessa questão mobiliza um conjunto grande de passos associados a diferentes conceitos e valores. A necessidade de muitas operações em sequência amplia a chance de erros matemáticos ou conceituais.

A alternativa errada com maior frequência é a $\left(\mathrm{D}, 2,4 \mathrm{~g} / \mathrm{cm}^{3}\right)$. Uma possível explicação para essa opção seria que os alunos interpretaram o valor da força resultante no dinamômetro como o valor da força de empuxo. Um segundo ponto é que o cubo é considerado completamente mergulhado, como pode ser visto na expressão a seguir:

$$
\rho=\frac{24 \times 10^{5}}{10^{3} \times 10 \times 10 \times 10}=2,4 \frac{\mathrm{g}}{\mathrm{cm}^{3}}
$$


A tensão na prova associada ao imediatismo e ao treinamento em exercícios de fixação (aplicação simples de fórmulas), dificulta ao aluno refletir - tanto sobre o método de resolução, quanto na análise dos valores encontrados. O resultado numérico obtido para a densidade da água igual a 2,4 g/ $\mathrm{cm}^{3}$, próxima da densidade do alumínio $\left(2,7 \mathrm{~g} / \mathrm{cm}^{3}\right)$ não é contextualizado.

No caso de itens de múltipla escolha, muitas vezes o aluno valida seus cálculos comparando o resultado obtido com as alternativas apresentadas, sem que haja - por falta de tempo ou por falta de conhecimento - uma reflexão conceitual sobre o algoritmo adotado ou numérica sobre o resultado obtido. No caso dessa alternativa, a resposta poderia ser simplesmente por que o último valor numérico apresentado na questão era $24 \mathrm{~N}$ e existia uma alternativa com um valor com os mesmos números, $2,4 \mathrm{~g} / \mathrm{cm}^{3}$.

Outra maneira de observar o esquema proposto na questão é imaginar que o bloco flutua no lago, com metade de seu volume fora da água. Alunos com uma visão parcial do conceito de densidade optariam por calcular a densidade como uma razão direta entre metade da massa do bloco (associada ao volume submerso) e o volume do bloco. Essa operação conduz à alternativa $\left(\mathrm{C}, 1,5 \mathrm{~g} / \mathrm{cm}^{3}\right)$. Existe um raciocínio intuitivo que sustenta essa escolha, associando conceitos de volume, empuxo e equilíbrio de forças (CLEMENT, 1994).

Temos a seguir uma das raras questões puramente conceituais da prova, onde podemos identificar a presença de concepções não científicas.

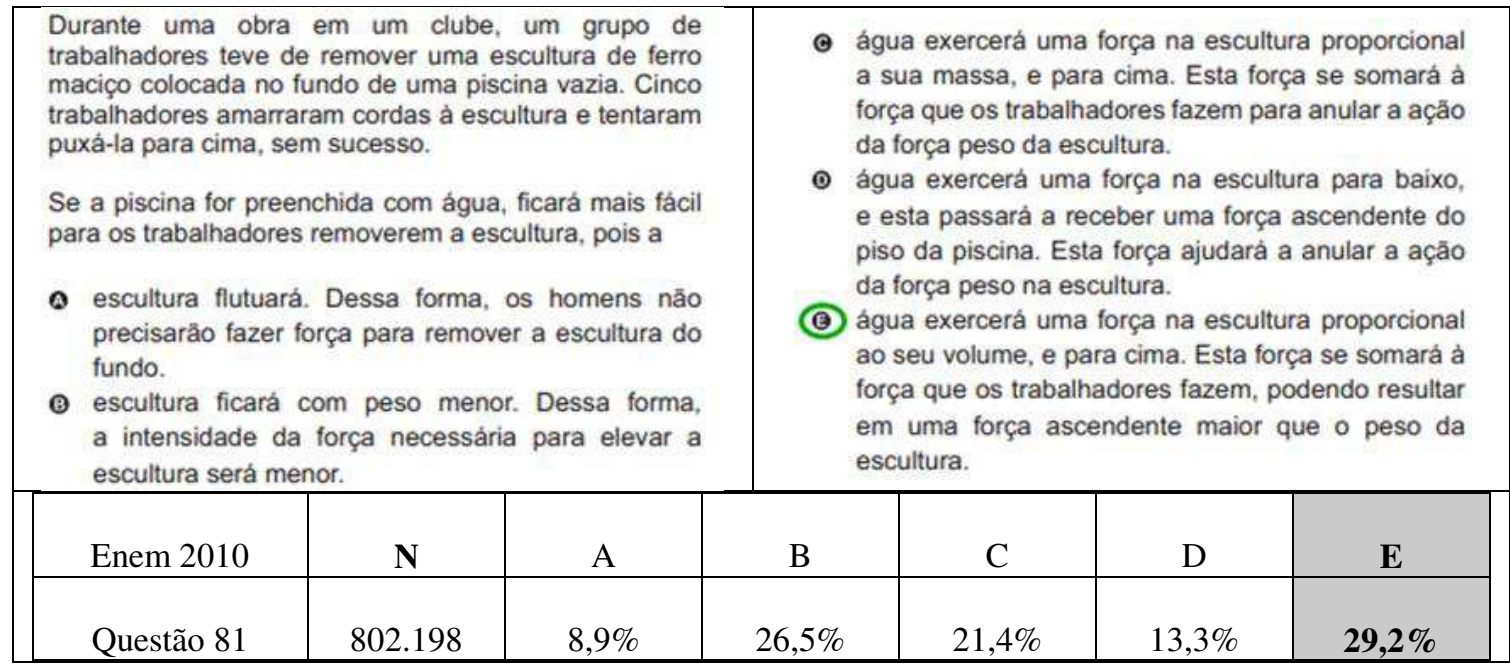

Fig. 6-Escultura na piscina.

As análises sobre a frequência de respostas dos candidatos mostram que $50 \%$ dos candidatos assinalou os distratores (B) e (C), associadas a "diminuir o peso" e "anular o peso". Diminuir o peso dentro da água é uma concepção não científica bastante comum, como podemos supor a partir da taxa de respostas em (B), onde se confunde a força resultante com o peso da estátua, desconsiderando o empuxo. 
Relacionar o empuxo com a massa em vez do volume de água deslocado reflete outra falha conceitual, representada pela alternativa (C). Isso indicaria, novamente, uma relação direta com a ideia de "anular o peso" para levantar um objeto, uma vez que a massa é diretamente proporcional a força peso. Logo, se existe uma força que seja contraria ao peso, essa força, consequentemente, também deve ser proporcional a massa.

Nossa próxima questão relaciona-se com uma situação cotidiana, onde o candidato deve associar os conceitos de coluna de água e pressão, em uma situação doméstica com distâncias entre a caixa d'água e a ducha.

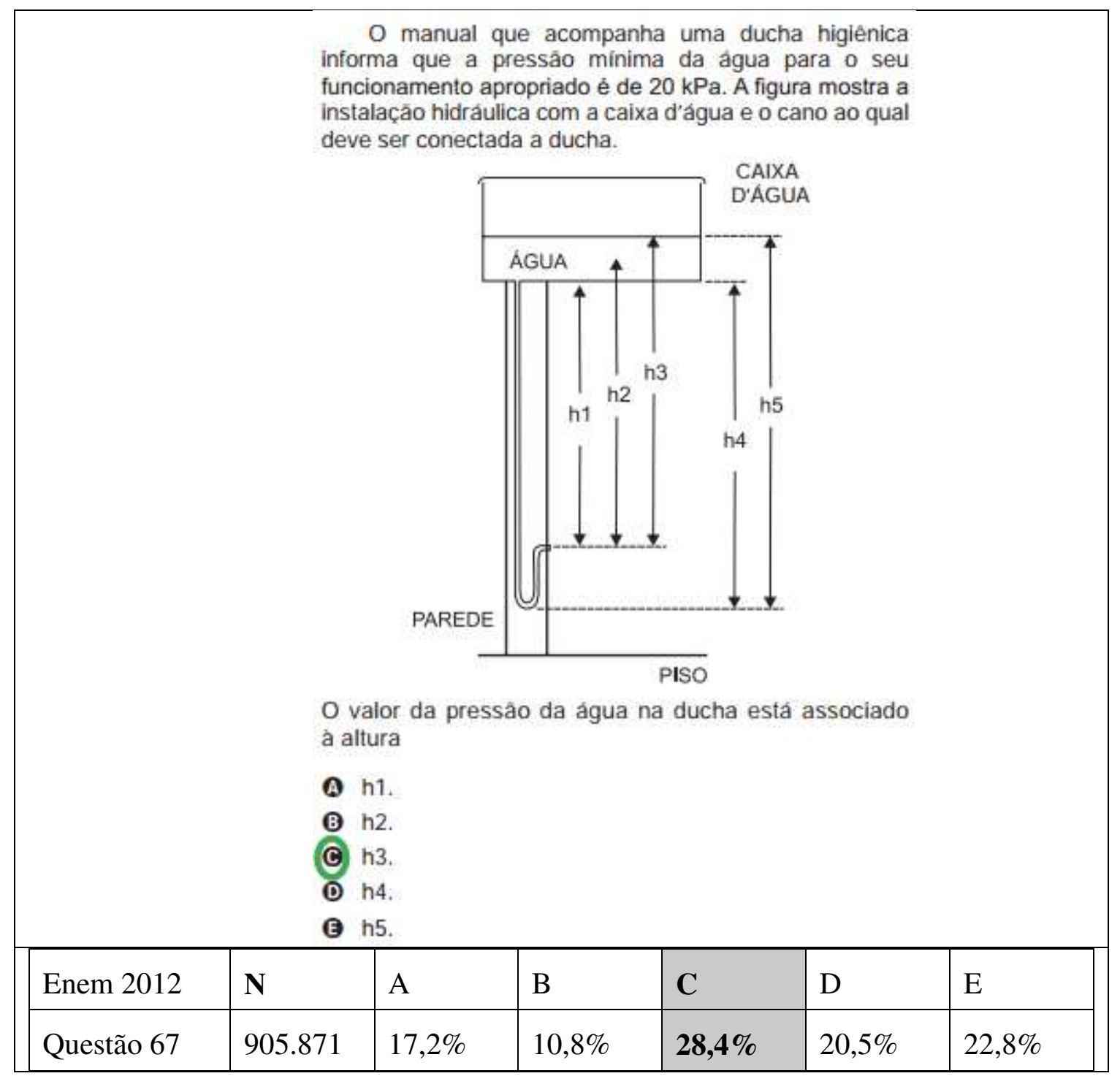

Fig. 7 - Coluna de água em uma casa.

O que é apresentado aos alunos é um esquema simplificado do sistema hidráulico de uma casa para que os candidatos possam analisar as cinco alturas (h) diferentes e escolher qual 
delas irá determinar a pressão da água da ducha. Na resolução o aluno necessita utilizar o conceito de pressão hidrostática, relacionando a altura da coluna de água com a pressão.

Ainda que a alternativa correta apresente uma taxa razoável de respostas, temos que as alternativas erradas (D) e (E) atraem mais de $40 \%$ dos candidatos. Ambas as alternativas associam a pressão à maior altura do cano, partindo desde o ponto de altura mínima do cano até a altura máximo (que não é a mesma em ambos os casos). Todos esses alunos desconsideram o efeito de sifão entre a altura mínima do cano e a saída para a ducha higiênica.

Ao comparar a altura superior, temos outra concepção errônea, essa associada ao fato de que a coluna de água está associada ao cano (em uma associação quase arquitetônica entre o cano e a coluna, ambos como tubos), sendo que a altura da água na caixa de água não alteraria a pressão. Em ambos os casos, fica aparente a dificuldade dos alunos com questões relativas a vasos comunicantes, seja pelo efeito do sifão, seja pela coluna de água.

Uma questão que pode causar dúvidas sobre sua pertinência na prova (apesar de trazer informações muito interessantes sobre a compreensão de corpos rígidos) refere-se às forças que agem nas dobradiças de uma porta. Sua solução requer reconhecer a porta como um corpo rígido (e não uma partícula) e a utilização de um diagrama vetorial de forças.

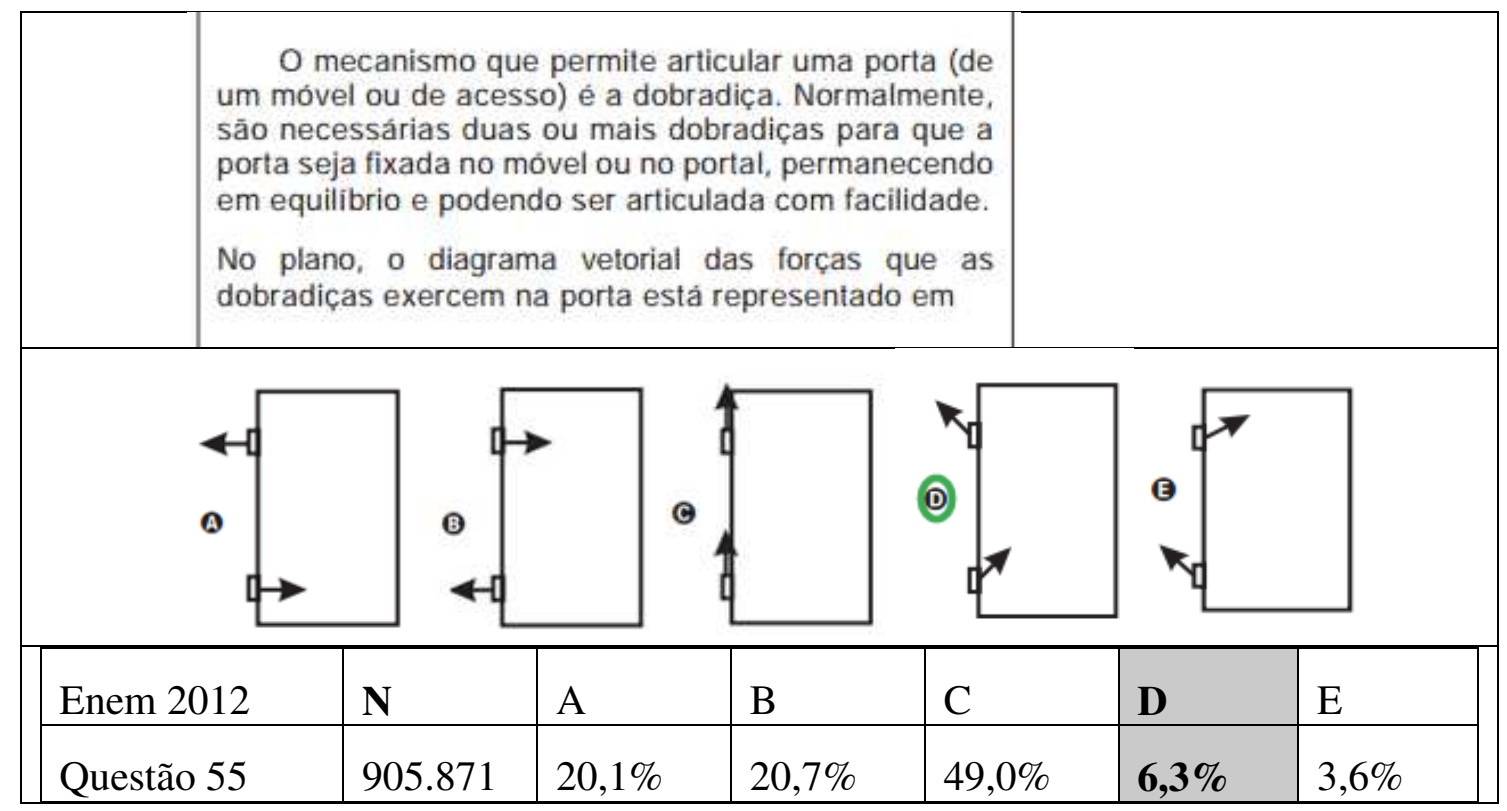

Fig. 8-Analisando as forças sobre as dobradiças das portas.

Metade dos alunos descreve as forças na vertical, agindo sobre as dobradiças (alternativa C). Essa disposição dos vetores provavelmente é associada ao fato de que a porta não é tratada como um corpo sólido, mas sim como um corpo pontual, uma "partícula com massa da porta $m_{P}$ ". Sempre que existe uma partícula, o seu diagrama vetorial indica que a força peso tem direção vertical e sentido para "baixo"; logo os vetores associados à força das dobradiças 
teriam a mesma direção e sentido contrário (para "cima"), de forma a manter o equilíbrio do sistema.

Esse é um problema muito difícil, provavelmente fora do escopo do Ensino Médio comum. Porém, ele traz informações sobre o quanto os alunos estão "treinados" em transformar todas as situações reais em modelos associados a partículas de massa $\mathrm{m}$.

As demais alternativas implicam em um reconhecimento da porta como um corpo rígido. Nota-se uma igualdade na frequência de respostas dos distratores (A) e (B). Nesses, a força nas dobradiças é na direção horizontal, sendo alternado o sentido entre a dobradiça superior e a dobradiça inferior. A direção horizontal dos vetores pode sugerir uma concepção não cientifica ligada ao fato de que os parafusos utilizados nas dobradiças são colocados na direção horizontal, e consequentemente a força deve ser horizontal. A diferença no sentido das forças está (provavelmente) associada à uma interpretação associada às abas das dobradiças, sobre em qual aba de cada dobradiça (uma aba na porta e outra aba na parede) a força está sendo exercida.

Somente como o conceito de torque muito bem definido é que é possível resolver essa questão, sendo que somente $10 \%$ dos candidatos optaram por alternativas onde o torque está presente. Novamente, se faz presente a diferença entre a força que a dobradiça exerce na porta ou na parede.

Apresentamos agora uma situação problema associada com a compactação do solo devido às operações agrícolas. Essa questão necessita por parte dos alunos do domínio das diferenças associadas entre os conceitos de força e de pressão.

\begin{tabular}{|c|c|c|c|c|c|c|}
\hline \multicolumn{3}{|c|}{$\begin{array}{l}\text { Um dos problemas ambientais vivenciados pela } \\
\text { agricultura hoje em dia é a compactação do solo, devida } \\
\text { ao intenso tráfego de máquinas cada vez mais pesadas, } \\
\text { reduzindo a produtividade das culturas. } \\
\text { Uma das formas de prevenir o problema de compactaçāo } \\
\text { do solo e substituir os pneus dos tratores por pneus mais }\end{array}$} & \multicolumn{4}{|c|}{$\begin{array}{l}\text { (A) largos, reduzindo a pressão sobre o solo. } \\
\text { B estreitos, reduzindo a pressāo sobre o solo. } \\
\text { C largos, aumentando a pressão sobre o solo. } \\
\text { (D) estreitos, aumentando a pressão sobre o solo. } \\
\text { (E) altos, reduzindo a pressão sobre o solo. }\end{array}$} \\
\hline Enem 2012 & $\mathbf{N}$ & $\mathbf{A}$ & B & $\mathrm{C}$ & $\mathrm{D}$ & $\mathrm{E}$ \\
\hline Questão 47 & 905.871 & $37,1 \%$ & $35,6 \%$ & $4,4 \%$ & $3,0 \%$ & $19,6 \%$ \\
\hline
\end{tabular}

Fig. 9 - Compactação do solo devido as máquinas agrícolas.

As três alternativas com maior índice de resposta estão associadas com a diminuição da pressão sobre o solo (alternativas A, B e E). As frequências das alternativas (A) e (B) são praticamente iguais, sendo a diferença entre as duas a largura dos pneus. Uma das possibilidades de um grande número de alunos terem optado por pneus estreitos seria a associação da pressão à largura dos rastros do pneu: quanto mais largo o rastro maior a pressão, sugerindo a utilização de uma concepção não científica de origem sensorial.

Já os candidatos que optaram pela alternativa (E, 20\%) utilizaram, provavelmente, uma concepção não científica com origem sensorial, a qual objetos maiores apresentam o peso melhor distribuído. Da mesma forma, que o vetor força peso está mais distante do chão, gerando 
assim uma menor pressão. Sendo assim, quanto mais alto for o objeto menor será a pressão por ele exercida sobre uma superfície (PARTHARE; PRADHAN, 2004).

As análises sobre as duas últimas questões mostram que quando os candidatos são expostos a um problema contextualizado e real acabam utilizando de concepções não científicas na resolução do problema. Sendo essas concepções formadas fora da escola através de experiências sensoriais (POZO; GOMES CRESPO, 2009).

\section{Conclusão}

Nesse trabalho buscamos apresentar análises sobre os distratores mais assinalados pelos candidatos nas questões de Física presentes nas provas do Enem, nos anos de 2009 a 2012. As análises revelaram a existência de um conjunto grande de erros presentes no conhecimento escolar desses candidatos. Esses erros possibilitam a construção de uma matriz de dificuldades desses candidatos, a saber: a não utilização correta das unidades de medidas, a presença das formas simbólicas (SHERIN, 2001), raciocínios intuitivos (CLEMENT, 1994) na resolução dos problemas, conceitos não científicos (KOU et al., 2013) e a análise incorreta de imagens presentes na situação proposta (BEICHNER, 1994; BERG; SMITH, 1994). Esse tipo de levantamento de erros apresentado nesse artigo possibilita compreender algumas dificuldades dos alunos da rede pública de ensino e assim fornecer um conjunto de informações importantes para os seus professores.

Desta forma, propomos que a utilização dos exames em larga escala associados as análises aqui apresentadas das dificuldades dos alunos a partir das estratégias de resolução de problemas, possibilita a esses exames tornarem-se um instrumento, dentro de suas limitações, de avaliação com características formativas. Para isso as análises sobre os erros cometidos pelos alunos devem retornar às escolas, promovendo uma realimentação do sistema, a qual é essencial para o desenvolvimento de uma avaliação formativa (TARAS, 2010; BLACK, 2009).

Esse retorno em primeira instância deveria ser feito pelo INEP, como as devolutivas pedagógicas dos resultados da Prova Brasil//SAEB ${ }^{5}$, uma vez que é o órgão ligado ao Ministério da Educação responsável pelo Enem e as outras avaliações da Educação Básica. Contudo, acreditamos que pesquisas acadêmicas poderiam, também, promover esse retorno as escolas, da mesma forma que ampliariam as discussões sobre esses exames que afetam os jovens no Brasil, como é o caso do Enem.

Sendo assim, entender essa proximidade entre a avaliação formativa e a avaliação somativa é essencial para ressignificação os resultados dos exames de larga escala, tornando-os úteis para a comunidade escolar, principalmente úteis para a melhoria do Ensino de Física das escolas públicas.

\footnotetext{
${ }^{5}$ Disponível em: <http://devolutivas.inep.gov.br/login>.
} 


\section{Agradecimentos}

Um dos autores, MARCOM, G.S., foi apoiado pela Coordenação de Aperfeiçoamento de Pessoal de Nível Superior (CAPES). Esse trabalho foi apoiado parcialmente pelo projeto MEC/INEP/DIRED, intitulado "A Prova do Enem: Impacto das Variáveis Cognitivas, Econômicas e Sociais no Desempenho".

\section{Referências}

ANDRADE, G. G. A Metodologia do Enem: uma reflexão. Séries - Estudos, Campo Grande, n. 33, p. 67-77, jan./jul. 2012.

ANDRIOLA, W. B. Doze motivos favoráveis à adoção do Exame Nacional do Ensino Médio (ENEM) pelas Instituições Federais de Ensino Superior (IFES). Ensaio: avaliação, políticas públicas e Educação, Rio de Janeiro, v. 19, n. 70, p. 107-126, jan./mar. 2011. Disponível em: < http://www.scielo.br/pdf/ensaio/v19n70/v19n70a07.pdf>. Acesso em: 18 jun. 2015.

BASSALO, J. M. F. Questões de Física do ENEM/2009. Caderno Brasileiro de Ensino de Física, Florianópolis, v. 28, n. 3, p. 325-355, ago. 2011.

BEICHNER, R. J. Testing student interpretation of kinematics graphs. American Journal of Physics, College Park, v. 62, n. 8, p. 750-762, ago. 1994. Disponível em:

<https://www.ncsu.edu/per/Articles/TUGKArticle.pdf>. Acesso em: 15 jun. 2015.

BERG, C. A.; SMITH, P. Assessing students' abilities to construct and interpret line graphs: disparities between multiple-choice and free-response instruments. Science Education, v. 78, n. 6, p. 527-554, nov. 1994. Disponível em:

<http://onlinelibrary.wiley.com/doi/10.1002/sce.3730780602/abstract>. Acesso em: 15 jun. 2015.

BLACK, P. Os professores podem usar a avaliação para melhorar o ensino?. Práxis Educativa, Ponta Grossa, v. 4, n. 2, p. 195-201, jul/dez. 2009.

CHI, M. T. H.; FELTOVICH, P. J.; GLASER, R. Categorization and representation of physics problems by experts and novices. Cognitive Science, Wheat Ridge, v. 5, n. 2, p. 121-152, abr. 1981. Disponível em:

$<$ http://onlinelibrary.wiley.com/doi/10.1207/s15516709cog0502_2/epdf>. Acesso em: 10 jun. 2015.

CHI, M. T. H.; GLASER, R.; REES, E. Expertise in problem solving. In: STERNBERG, R. J. (Org.). Advances in the psychology of human intelligence, v. 1. Hillsdale, NJ: Erlbaum, 1982. p. 7-75. 
CLEMENT, J. Use of physical intuition and imagistic simulation in expert problem solving. In: TIROSH, D. (Org.). Implicit and explicit knowledge. Norwood, NJ: Ablex, 1994. p. 204- 244.

DUARTE, L. P. A. A.; GONÇALVES JR, W. P.; BARROSO, M. F. Estudo de um item quantitativos na prova de física do Enem 2009. In: SIMPÓSIO NACIONAL DE ENSINO DE FÍSICA, XX, 2013, São Paulo. Anais... São Paulo: SBF, 2013. Disponível em: <http://www.if.ufrj.br/ marta/enem/producao_enem/Snef2013_T0455-1.pdf>. Acesso em: 10 jun. 2015.

FERNANDES, D. Avaliar para Aprender: Fundamentos, práticas e políticas. São Paulo: Unesp, 2009. 244 p.

GOMES, C. M. A. Avaliando a avaliação escolar: notas escolares e inteligência fluida. Psicologia em Estudo, Maringá, v. 15, n. 4, p. 841-849, oct/dez. 2010. Disponível em: $<$ http://www.scielo.br/scielo.php?pid=S1413-73722010000400020\&script=sci_arttext>. Acesso em: 10 jan. 2016.

GOMES, C. M. A.; BORGES, O. N. O ENEM é uma avaliação educacional construtivista? Um estudo de validade de constructo. Estudos em Avaliação Educacional, São Paulo, v. 20, n. 42, p. 73-88, jan./abr. 2009. Disponível em: <http://www.fcc.org.br/pesquisa/publicacoes/eae/arquivos/1468/1468.pdf>. Acesso em: 10 jan. 2016.

GONÇALVES JR, W. P.; BARROSO, M. F. As questões de física e o desempenho dos estudantes no ENEM. Revista Brasileira de Ensino de Física, São Paulo, v. 36, n. 1, p. 1-11, jan./mar. 2014.

GONÇALVES JR, W. P.; BARROSO, M. F. Enem: as questões e o desempenho dos estudantes em 2009. In: ENCONTRO DE PESQUISA EM ENSINO DE FÍSICA, XIV, 2013, Maresias. Anais... Maresias. 2013. Disponível em: <http://www.if.ufrj.br/ marta/enem/producao_enem/EPEF2012_T0110-1.pdf>. Acesso em: 11 jun. 2015.

HALE, P. Kinematics and graphs: students' difficulties and CBLs. Connecting Research to Teaching, Reston, v. 93, n. 5, p. 414-417, mai. 2000. Disponível em: <http://math.buffalostate.edu/ mcmillen/Hale.pdf>. Acesso em: 10 jun. 2014.

INSTITUTO NACIONAL DE ESTUDOS E PESQUISAS EDUCACIONAIS ANÍSIO TEIXEIRA (INEP). ENEM: Documento Básico. Brasília, 2002. Disponível em: <http://www.publicacoes.inep.gov.br/portal/download/265>. Acesso em: 2 jan. 2014.

INSTITUTO NACIONAL DE ESTUDOS E PESQUISAS EDUCACIONAIS ANÍSIO TEIXEIRA (INEP). Enem (Exame Nacional do Ensino Médio): Matriz de Referência para o Enem 2009. Brasília, 2009. Disponível em: <http://ensinomediodigital.fgv.br/resources/pdf/matriz_novoenem.pdf>. Acesso em: 2 jan. 2014. 
INSTITUTO NACIONAL DE ESTUDOS E PESQUISAS EDUCACIONAIS ANÍSIO TEIXEIRA (INEP). Guia de Elaboração e Revisão de Itens. Brasília, 2010.

KOHL, P. B.; FINKELSTEIN, N. D. Effects of representation on students solving physics problems: A fine-grained characterization. Physical Review Special Topics - Physics Education Research, Riged, v. 2, n.1, p. 010106-1-010106-12, mai. 2006. Disponível em: <http://journals.aps.org/prper/abstract/10.1103/PhysRevSTPER.2.010106>. Acesso em: 20 ago. 2015.

KUO, E. et al. How students blend conceptual and formal mathematical reasoning in solving Physics problems. Science Education, v. 97, n. 1, p. 32-57, jan. 2013. Disponível em: <http://onlinelibrary.wiley.com/doi/10.1002/sce.21043/full>. Acesso em: 20 ago. 2015.

LARKIN, J.; MCDERMOTT, J.; SIMON, D.P.; SIMON, H. A. Expert and novice performance in solving physics problems. Science, v. 208, n. 4450, p. 1335-1342, jun. 1980. Disponível em: < http://science.sciencemag.org/content/208/4450/1335.abstract>. Acesso em: 20 ago. 2015.

LOZADA, C. O.; ARAÚJO, M. S.T.; MARRONE, W.; AMARAL, L. H. A modelagem matemática aplicada ao ensino de Física no Ensino Médio. Revista Logos, São José do Rio Pardo, n. 14, p. 2-12, 2006. Disponível em: <http://www.feucriopardo.edu.br/logos/artigos/2006b/ARTIGO1-pag2-ClaudiaLozada-logos-14-2006.pdf>. Acesso em: 10 jan. 2016.

MALONEY, D. P. An overview of physics education research on problem solving. Getting Started in Physics Education Research, College Park, v. 1, n. 2, p. 1-33, set. 2011. Disponível em: <http://opus.ipfw.edu/physics_facpubs/49/>. Acesso em: 10 jan. 2014.

MARCOM, G. S. O ENEM com indicador qualitativo para o ensino: uma aplicação às questões de Física. 2015. 211f. Dissertação (Mestrado em Ensino de Ciências e Matemática) - Instituto de Física Gleb Wataghin, UNICAMP, Campinas.

MARCOM, G. S.; KLEINKE, M. U. Questões do ENEM e suas relações com o Ensino de Física. In: ENCONTRO NACIONAL DE PESQUISA EM EMDUCAÇÃO EM CIÊNCIAS, X, 2015, Águas de Lindóia. Anais... Águas de Lindóia. 2015.

MARCOM, G. S.; KLEINKE, M. U. O ENEM como instrumento de análise do ensino de física. In: ENCONTRO DE PESQUISA EM ENSINO DE FÍSICA, XV, 2014, São Sebastião. Anais... São Sebastião. 2014.

OLIVEIRA. C. F. et al. Contextualização e desempenho em exames de Ciências da Natureza: O "Novo Enem". In: ENCONTRO NACIONAL DE PESQUISA EM EDUCAÇÃO EM CIÊNCIAS, IX, 2013, Águas de Lindóia. Anais... Águas de Lindóia. 2013. Disponível em: $<$ http://sites.ifi.unicamp.br/kleinke/files/2014/01/Contextualizacao-e-desempenho-no-novoEnem.pdf>. Acesso em: 10 ago. 2015.

PATHARE S.; PRADHAN, H. C. Students' alternative conceptions in Pressure, Heat and Temperature. In: INTERNATIONAL CONFERENCE TO REVIEW RESEARCH ON SCIENCE, 
TECHNOLOGY AND MATHEMATICS EDUCATION, I, 2004, Goa, Índia. Anais... Goa, Índia. 2004.

PERRENOUD, P. Avaliação: da excelência à regulação das aprendizagens. Porto Alegre: Artmed, 1999. $184 \mathrm{p}$.

POZO, J.; GÓMEZ CRESPO, M. A. A aprendizagem e o ensino de ciências: do conhecimento cotidiano ao conhecimento científico. Porto Alegre: Artmed, 2009. 294p.

SABELLA, M. S.; REDISH, E. Knowledge organization and activation in physics problem solving. American Journal of Physics, Melville, v. 75, n. 11, p. 1017-1029, mai. 2007. Disponível em: <http://scitation.aip.org/content/aapt/journal/ajp/75/11/10.1119/1.2746359>. Acesso em: 10 ago. 2015.

SADAGHIANI, H; AGUILERA, N. Mathematical vs. conceptual understanding: where do we draw the line?. In: PHYSICS EDUCATION RESEARCH CONFERENCE, 2012, Philadelphia, v. 1513, p. 358-361, jan. 2013. Disponível em: <http://scitation.aip.org/content/aip/proceeding/aipcp/10.1063/1.4789726>. Acesso em: 10 ago. 2015.

SILVEIRA, F. L.; BARBOSA, M. C. B.; SILVA, R. Exame Nacional do Ensino Médio (ENEM): Uma análise crítica. Revista Brasileira de Ensino de Física, São Paulo, v. 37, n. 1, p. 1101, mar. 2015.

SILVEIRA, F. L.; STILCK, J.; BARBOSA, M. Comunicações: Manifesto sobre a qualidade das questões de Física na Prova de Ciências da Natureza no Exame Nacional de Ensino Médio. Caderno Brasileiro de Ensino de Física, Florianópolis, v. 31, n. 2, p. 473-479, ago. 2014.

SHERIN, B. L. How Students Understand Physics Equations. Cognition And Instruction, v. 19, n. 4, p. 479-541, 2001. Disponível em: <http://www.tandfonline.com/doi/abs/10.1207/S1532690XCI1904_3>. Acesso em: 10 ago. 2015.

TRAVITZKI, R. ENEM: limites e possibilidades do Exame Nacional do Ensino Médio enquanto indicador de qualidade escolar. 2013. 277f. Tese (Doutorado em Educação) - Programa de Pós-Graduação em Educação, Universidade de São Paulo, São Paulo.

TARAS, M. De volta ao básico: definições e processos de avaliação. Práxis Educativa, Ponta Grossa, v. 5, n. 2, p. 123-130, jul./dez. 2010. Disponível em: <http://www.revistas2.uepg.br/index.php/praxiseducativa/article/viewFile/1828/1385>. Acesso em: 10 ago. 2015. 